\title{
GRAMSCI E O DEBATE SOBRE A ESCOLA PÚBLICA NO BRASIL
}

\author{
ROSEMARY DORE
}

\begin{abstract}
RESUMO: Com o fim da ditadura militar no Brasil, as pressões sociais e políticas advindas dos movimentos populares colocaram para os setores progressistas da sociedade o desafio de formular projetos para democratizar o país. No campo educacional, o debate político sobre as diretivas para organizar a escola pôs em confronto duas grandes concepçôes. De um lado, a noção de "aparelho ideológico de Estado", proposta por Louis Althusser, e, de outro, a idéia de que a escola é "aparelho 'privado' de hegemonia”, baseada na reflexão de Antonio Gramsci. $\mathrm{O}$ confronto entre as duas noçôes de escola e os problemas da assimilação do pensamento gramsciano na área educacional, cujos efeitos alcançam a atualidade, é o objeto de análise deste ensaio.
\end{abstract}

Palavras-chave: Aparelho ideológico do Estado. Aparelho privado de hegemonia. Escola pública. Escola unitária. Gramsci.

\section{GRAMSCI AND THE DEBATE ABOUT PUBLIC SCHOOL IN BRAZIL}

ABSTRACT: After the Brazilian military dictatorship, the social and political pressures exerted by popular movements challenged the most progressive groups of society to propose projects to democratize the country. In the area of education, the political debates concerning guidelines to organize school opposed two major conceptions: the notion of "ideological State apparatus", defended by Louis Althusser, and the idea that school is a "hegemonic 'private' apparatus", based on Antonio Gramsci's reflection. This paper explores the confrontation between both notions of schooling and the problems of assimilating Gramscian thoughts in the field of education, whose effects still persist.

Key words: Ideological State apparatus. Hegemonic 'private' apparatus. Public school. Unitary school. Gramsci.

Doutora em Educação e professora de Filosofia da Educação da Universidade Federal de Minas Gerais (UfMG).E-mail: rrosedore@yahoo.it 


\section{Introdução}

$\mathcal{N}$

a história da educação brasileira, a apresentação de propostas para a educação pública, a partir de uma perspectiva socialista, ocorre somente durante a década de 80 do século passado, quando tem início a redemocratização do país, no final de uma ditadura militar que durou vinte anos. Elas começaram a surgir em confronto com a noção de Louis Althusser (1974), segundo a qual a escola é um aparelho ideológico do Estado burguês. Suas idéias não encorajavam (e nem poderiam) a formulação de um projeto socialista para a escola pública. Ao contrário, esta passou a ser profundamente atacada, como se fosse um instrumento par excellence de dominação absoluta do capital. Foram as reflexôes de Antonio Gramsci (1978), mais difundidas nos anos de 1980, que contribuíram para formular projetos em defesa da educação pública e de qualidade para todos. Nesse período, enquanto o referencial gramsciano passou a orientar projetos para a escola pública e pesquisas em educação, as teorias da escola como aparelho de reprodução entraram em declínio (Silva, 1990, p. 155). Entretanto, a partir da década de 1990, a perspectiva gramsciana foi perdendo terreno.

$\mathrm{O}$ que teria acontecido? Por que a análise de Gramsci, tão fecunda a respeito dos problemas da cultura e da educação, sofreu um refluxo? Apresentar algumas indicaçóes que possam contribuir para elucidar o fenômeno é o objetivo deste artigo.

Escola pública: aparelho de reprodução social e cultural ou de hegemonia?

As noções formuladas por Louis Althusser a respeito do Estado capitalista começaram a ser divulgadas no Brasil ainda sob o clima da repressão social e política, imposto pela ditadura militar em meados da década de 1970. A novidade de sua análise era a noção de "aparelhos ideológicos de Estado”, dentre os quais se encontrava a escola.

Com o propósito de avançar a teoria marxista do Estado, Althusser (1974) parte da tese atribuída a Marx, segundo a qual a reprodução das relações de produção é uma exigência: reproduzir a força de trabalho e também a sujeição dos trabalhadores à ordem dominante. Para isso, o autor retoma o Prefácio (1859) à Contribuição para a crítica da economia 
política, no qual Marx enuncia a metáfora da estrutura e superestrutura como critério de análise da sociedade. De acordo com Marx, o conjunto das relações de produção

(...) forma a estrutura econômica da sociedade, a base real sobre a qual se levanta a superestrutura jurídica e política e à qual correspondem determinadas formas de consciência social. (...) Ao mudar a base econômica, revoluciona-se, mais ou menos rapidamente, toda a imensa superestrutura erigida sobre ela. (Marx, 1983, p. 24 e 25)

Althusser se reporta a essa metáfora e diz que ela constitui o "edifício" que explica a sociedade conforme a tese do "materialismo histórico". Para ele, na base do edifício está a economia, que é determinante de tudo o que está na superestrutura: as instâncias jurídicas, políticas e ideológicas. Estas últimas, por sua vez, não são determinantes, "em última instância", da base do edifício. Contudo, existiria uma "autonomia relativa" da superestrutura em relação à base, bem como uma ação recíproca entre estrutura e superestrutura. $\mathrm{O}$ autor ressalta que o aprofundamento do significado desses dois níveis, autonomia relativa e ação recíproca, só pode ser realizado dentro do ponto de vista da reprodução.

Althusser quer ir além da descrição da metáfora do "edifício" e assim retorna à teoria formulada por Marx e Engels em torno de 1848, e seguida por Lênin durante a revolução soviética (1917), de que o Estado é uma "máquina de repressão", para distinguir o poder de Estado do aparelho de Estado. O objetivo da luta de classe diz respeito ao poder de Estado, o qual deve ser apropriado pelo proletariado com o fim de destruir o Estado burguês. Após tomar o poder do Estado, o proletariado substitui o aparelho de Estado repressivo por outro, proletário, e em fases subseqüentes destrói completamente o Estado (Althusser, 1974, p. 38). Mas, além do "aparelho repressivo de Estado", o autor identifica os "aparelhos ideológicos de Estado", afirmando que Gramsci teria mostrado que o Estado não se reduziria apenas ao aparelho repressivo, embora suas anotaçôes sobre o assunto fossem fragmentárias (idem, ibid., p. 42, nota 1).

Segundo Althusser, o "aparelho repressivo de Estado", que agregaria a magistratura (o governo, a administração, os tribunais), as prisôes, a polícia e o exército, tem o papel de garantir, predominantemente pela força, as condições políticas para a reprodução das relações de produção, mas também pode atuar secundariamente pela ideologia. Já os "apare- 
lhos ideológicos de Estado", correspondentes à religião, educação, família, sindicato, a imprensa, os meios culturais etc., garantem, prevalentemente pela ideologia, a reprodução das relações de produção, embora também possam exercer a violência.

Ao formular o conceito de "aparelhos ideológicos de Estado", o autor se vê obrigado a explicitar seu conceito de ideologia. Afirma que a ideologia não tem história, constitui uma representação imaginária dos indivíduos com suas condiçôes reais de existência, pois é uma distorção das relações reais; a ideologia tem uma existência material e interpela os indivíduos como sujeitos. Os aparelhos ideológicos do Estado, por meio de suas práticas e rituais, realizam as ideologias e, assim, contribuem para reproduzir as relações de produção: garantem a opressão de classe e suas condições de exploração e reprodução.

Althusser situa a instituição educacional como um dos aparelhos ideológicos do Estado dominantes nas formações sociais capitalistas maduras (idem, ibid., p. 60-61). Como os aparelhos ideológicos do Estado reproduzem as relações de produção, então a escola realiza essa função. Por meio da aprendizagem, é massivamente inculcada a ideologia da classe dominante com o objetivo de reproduzir as relações de exploração que caracterizam a sociedade capitalista, embora esse mecanismo seja camuflado e a escola apresentada como um terreno neutro. Assim, é a ideologia que faz os sujeitos pensarem que o sistema escolar é universal, quando, ao contrário, ele serve para manter os interesses dos grupos dominantes.

No Brasil, o conceito da escola como um "aparelho ideológico do Estado" provocou grandes reviravoltas na área educacional. Na década de 1970, devido ao clima de cerceamento das liberdades civis e da difusão de idéias, as análises sobre a escola eram feitas à luz de enfoques que não criticavam sua relação com a sociedade capitalista. Mas essa situação começa a mudar no final da ditadura militar, quando é reforçada a leitura crítica da escola, secundada pela teoria da reprodução. É quando ganha força a análise de Bourdieu e Passeron (1975) sobre a educação na França, segundo a qual há estreita relação entre reprodução cultural e reprodução social. Não obstante Bourdieu e Passeron se inspirem num referencial weberiano (Morrow \& Torres, 1995, p. 187; Cunha, 1979, p. 101, nota 41), enquanto Althusser escolhe o marxismo, ambos afirmam um paradigma estruturalista de análise da sociedade. Sustentam que o papel da escola é o de reproduzir a estrutura social, por meio de 
um trabalho de "inculcação", de habitus para os primeiros e de ideologia para o segundo, favorável à manutenção de uma estrutura de classes.

A idéia de que a escola realiza uma reprodução social e cultural suscitou muitas críticas (Cunha, 1979), nas quais era destacada, principalmente, a ausência da categoria contradição, já que o esquema da reprodução parecia se realizar sem antagonismos de classe. Se essa teoria, seja no enfoque de Althusser ou de Bourdieu e Passeron, admite que o sistema escolar tem "autonomia relativa" do sistema econômico, em que consistiria tal autonomia, já que a função da escola é reduzida a legitimar a estrutura social?

Uma tentativa para responder ao problema da "autonomia relativa da escola” é apresentada pelos sociólogos franceses Baudelot e Establet (1976), que analisam o ensino primário na França à luz do conceito de "aparelhos ideológicos do Estado". Ali, os autores explicam que o aparelho escolar ocupa um lugar privilegiado na superestrutura do modo de produção capitalista, organizando-se em duas redes, de modo a reproduzir a divisão da sociedade em classes, os burgueses e os proletários, seja ao inculcar a ideologia dominante, seja ao formar a força de trabalho.

Establet (1974, p. 106) explica algumas noções que orientaram a pesquisa realizada junto a Baudelot, deixando claro um aspecto que, de resto, marca muitas abordagens sobre a reprodução: a dualidade entre escola e sociedade. Para o autor, existe uma "contradição principal" no capitalismo que, entretanto, está "brutalmente fora da escola sob a forma de uma luta que opõe a burguesia ao proletariado: ela se trava nas relações de produção, que são relações de exploração". Os objetivos perseguidos pelo Estado burguês são "exteriores à escola (ela só é um instrumento destinado a estes fins)”. A ideologia proletária, por sua vez, também existe "fora da escola nas massas operárias e suas organizações" (Establet, 1974, p. 106). Com essa dicotomia entre escola e sociedade, Establet encontra na escola apenas alguns efeitos da ideologia proletária, que "se apresentam como resistências: no entanto, inclusive através destas resistências, é ela [a ideologia proletária] que é visada no horizonte pelas práticas de inculcação ideológica burguesa e pequeno burguesa” (idem, ibid.).

Assim, é "fora" da escola que se realiza a contradição "principal" do capitalismo. Qual contradição? O confronto de classes sociais. Fora? Onde? Na economia, "nas relações de produção". Na "estrutura". Já no 
âmbito da escola, da "superestrutura", não há confronto. Há, no máximo, resistência.

Outra análise difundida no Brasil foi a de Poulantzas (1973), o qual se manifesta em desacordo com a tese de Althusser de que a escola é o aparelho ideológico dominante do modo de produção capitalista. Ele afirma que Gramsci foi o primeiro a explicitar "a concepção dos aparelhos ideológicos do Estado", atribuindo destaque ao "aparelho sindical de colaboração de classe” (Poulantzas, 1973, p. 128). Tal identificação entre o pensamento althusseriano e gramsciano a respeito do conceito de "aparelhos ideológicos", entretanto, não encontra respaldo nos Cadernos do cárcere (1977). Aí, Gramsci não enuncia em nenhum momento a noção de "aparelho ideológico do Estado", uma elaboração própria de Althusser.

Paralelamente à onda francesa de análise da escola sob o enfoque da teoria da reprodução, também chegaram ao Brasil, ainda nos anos de 1970, abordagens similares vindas dos Estados Unidos, como a de Bowles e Gintis (1976). Para os sociólogos norte-americanos, em lugar de promover a igualdade de oportunidades, a escola perpetua as formas de consciência, de comportamento e personalidade, exigidas para a reprodução das relações capitalistas de produção. Outra análise nessa mesma linha, também difundida no Brasil, foi a de Carnoy (1977, p. 14), de acordo com a qual a educação formal constitui parte da dominação imperialista, atuando em consonância com os interesses que convêm ao colonizador.

No clima de críticas demolidoras da escola pública, também floresceram no Brasil abordagens como as de Illich (1973), considerando a escola uma organização desnecessária. Embora não adote o conceito de reprodução presente nas vertentes francesa ou americana, Illich acaba sustentando que a escola reproduz a estratificação social e defendendo o seu fim como instituição educacional, já que as pessoas podem aprender e se educar sem ir à escola (Illich, 1973, p. 63). Na esteira da proposta de Illich para "desescolarizar" a sociedade, apareceram no Brasil as perspectivas de Postman (1971, p. 207), que também denuncia as escolas públicas, acusadas de reprovarem sistematicamente as crianças e, assim, reforçarem a desigualdade, e de Reimer (1975, p. 107), para quem a educação é extremamente importante para ser deixada ao cuidado das escolas públicas. 
As críticas contundentes à escola pública vinham de intelectuais cujos países de origem, Estados Unidos, França e Inglaterra, tinham universalizado a escola fundamental e média. No Brasil, que sequer tinha universalizado as primeiras séries do ensino fundamental, houve uma forte tendência em abandonar a escola pública (Paiva, 1985, 1985a, 1986; Gadotti, 1992), vista como aparelho ideológico a serviço da reprodução do Estado burguês (Saviani, 1985), o que abria espaços para os grupos privados expandirem seus interesses em comercializar o ensino.

A maior abertura política do país, a partir do início dos anos de 1980, alargou as possibilidades de manifestaçóes sociais em favor da escola pública, dando impulso às críticas aos limites das teorias de que a instituição educacional cumpria o simples papel de reprodução social e cultural. Nesse contexto, as reflexões de Gramsci sobre o Estado e a escola passaram a constituir uma importante referência para criticar a idéia de que a educação e a cultura, estando na "superestrutura", eram mecanicamente determinadas pela estrutura econômica. Ao contrário das tendências então dominantes, Gramsci conferia à educação e à cultura uma importância que estas jamais desfrutaram no pensamento socialista.

Se Gramsci não foi professor e nem pedagogo, mas um militante do Partido Comunista Italiano, por que a escola assumiu para ele importância tão decisiva?

O interesse de Gramsci pela educação e pela escola desenvolve-se no mesmo passo em que ele amplia seu estudo sobre o Estado capitalista e rompe com as teorias dominantes no movimento socialista, segundo as quais as idéias não tinham importância, sendo apenas um produto do domínio do capital.

Ao seu processo de ruptura foi fundamental, em primeiro lugar, recuperar a leitura dialética de algumas formulações de Marx. Não por acaso, Gramsci recorda frequentemente o Prefácio de 1859 à Contribuição à crítica da economia política (Marx, 1983) para ressaltar que Marx vivia num ambiente cultural marcado por tensóes entre idealismo e materialismo vulgar, atacando esses dois extremos para sustentar uma análise dialética da realidade. Muitas vezes, porém, suas críticas para superar o idealismo radicalizavam elementos de uma visão oposta, a materialista: "O modo de produção da vida material condiciona o processo da vida social, política e espiritual em geral. Não é a consciência do homem que determina o seu ser, mas, pelo contrário, o seu ser social é que determina a 
sua consciência" (Marx, 1983, p. 24; grifo meu). Aí se destaca mais o seu lado contendor, político, do que filosófico e científico. Já em outro momento do Prefácio, Marx afirma a importância das ideologias para que os homens tomem consciência dos conflitos sociais:

Quando se estudam essas revoluções [sociais], é preciso distinguir sempre entre as mudanças materiais, ocorridas nas condições econômicas de produção e que podem ser apreciadas com a exatidão própria das ciências naturais, e as formas jurídicas, politicas, religiosas, artísticas ou filosóficas, numa palavra, as formas ideológicas em que os homens adquirem consciência desse conflito e lutam para resolvê-lo. (Marx, 1983, p. 25; grifo meu)

Gramsci ressalta essa tensão e observa que, se o marxismo, como filosofia política, também fundamenta a crítica social, é necessário distinguir quando as idéias de Marx expressam princípios de polêmica e quando elas se referem a princípios gnosiológicos. Esse é um critério metodológico imprescindível para evitar transformar um princípio de polêmica num princípio de conhecimento (Gramsci, 1977, p. 1.595).

Em segundo lugar, Gramsci realizou uma leitura dialética da análise de Marx sobre a relação entre estrutura e superestrutura. Nos Cadernos do cárcere, ele volta várias vezes àquela citada afirmação de Marx, de acordo com a qual os homens tomam consciência dos conflitos sociais no nível das superestruturas (idem, ibid., p. 1.321, 1.501, 1.570, $1.583,1.592,1.595)$. Para Gramsci, as ideologias não são "aparência" ou "falsa consciência", mas constituem um terreno contraditório, no qual os conflitos sociais tanto podem ser ocultados quanto esclarecidos. Afirmar que é no terreno das ideologias que os homens tomam consciência dos conflitos de classe, pergunta Gramsci, "não é afirmar a necessidade e validade das 'aparências'?" (idem, ibid., p. 1.570).

A leitura dialética da relação entre materialismo e idealismo, entre estrutura e superestrutura, permite, por fim, questionar a noção de "materialismo histórico e dialético". A síntese dialética não tende para o sujeito, nem para o objeto; nem para a consciência, nem para a existência. Mas, na noção de "materialismo histórico e dialético", o pêndulo retorna para o material. $\mathrm{O}$ acento sobre a matéria não soluciona o problema proposto por Marx no estudo da sociedade, que é o de não resvalar nem para o idealismo e nem para o materialismo. É sugestivo que Gramsci, nos Cadernos do cárcere, chame o marxismo de "filosofia da práxis". Ali, 
ele oferece indicaçóes no sentido de que o problema da relação entre sujeito e objeto, consciência e existência, idealidade e materialidade, não tem uma solução metodológica, racional, mas uma solução histórica: teoria e prática, espírito e matéria se unificam dialeticamente no processo histórico. É a partir daí que trata a relação entre estrutura (economia) e superestrutura (ideologia) como uma relação discordante e contraditória num movimento histórico, o que corresponde ao conceito de bloco histórico (Gramsci, 1977, p. 1.051-1.052).

A crítica à leitura determinista do vínculo entre estrutura e superestrutura permite a Gramsci realizar uma nova análise do Estado capitalista, na qual ressalta a importância da dimensão da cultura e da educação - da "superestrutura" - para a conquista e manutenção do poder.

Gramsci procurou avançar o conceito de Estado elaborado por Marx e Engels, considerando as mudanças verificadas desde quando ele foi formulado, em torno de 1848 (Cf. o Manifesto do Partido Comunista, 197[_]). Compreendeu que o Estado já não governava apenas com base na força, na opressão dos trabalhadores, como tinha feito durante todo o século XIX, impedindo que os trabalhadores tivessem qualquer tipo de organização. A partir do final do século XIX, começaram a cair as proibiçōes ao direito dos trabalhadores de fazer greve, de constituir sindicatos, de votar, ser votado, de organizar partidos, de publicar jornais, dentre outras. A classe dominante abre sua sociedade para os seus inimigos. Ao mesmo tempo em que permite as manifestaçôes de seus adversários, o confronto de idéias, de posiçōes, ela busca convencer as classes subalternas a se submeterem ao seu domínio. Gramsci mostrou que essa forma da burguesia exercer o poder tinha novas características em relação às formas precedentes. Uma delas era a luta pela hegemonia.

A hegemonia significa que o Estado capitalista não baseia o seu poder apenas na força, na pura repressão aos seus adversários, embora a repressão não seja extinta. Para que os grupos dominantes obtenham o consenso na sociedade, eles permitem que os grupos subalternos se organizem e expressem seus projetos sociais e políticos. Com isso, vão se constituindo mediações entre a economia e o Estado, que se expressam na sociedade civil: o partido político, o sindicato, a imprensa, a escola. É um movimento próximo daquilo que Gramsci, certamente inspirado na reflexão de Hegel, entendeu como "trama privada", chamando a sociedade civil de "aparelho 'privado' de hegemonia" (Gramsci, 1977, p. 801). 
Se o surgimento da sociedade civil mostra o intenso trabalho educativo da classe dominante para garantir o consenso ao seu governo, ele também pode indicar formas de organização das classes subalternas para a conquista da hegemonia. Segundo Gramsci, um "grupo social pode e mesmo deve ser dirigente antes de conquistar o poder governativo (essa é uma das condiçóes principais para a própria conquista do poder); depois, quando exerce o poder e ainda que o empunhe fortemente, torna-se dominante, mas deve continuar também a ser 'dirigente" (idem, ibid., p. 2.010-2.011). A sociedade civil é o lugar no qual se dá a luta entre projetos sociais e políticos que são contraditórios entre si, no quadro da disputa pela hegemonia entre as classes sociais fundamentais. O poder dos grupos dominantes é exercido de forma repressora, mas também de forma "humana", porque ele busca e educa o consenso das classes subalternas. As duas dimensóes do poder formam, como sugere Gramsci retomando Maquiavel, a idéia de um centauro: meio selvagem, a repressão, e meio humana, a busca e a educação do consenso (idem, ibid., p. 1.576).

Se Gramsci entende a sociedade civil como "aparelho 'privado' de hegemonia”, em nenhuma parte dos Cadernos do cárcere, contudo, ele se refere ao conceito de "contra-hegemonia". Para ele, não se trata de permanecer no nível do "anti”, apenas negativo, tal como se caracteriza uma primeira fase de organização da burguesia em classe e em Estado (idem ibid., p. 1.053). Sua proposta é a de que as classes subalternas construam sua própria hegemonia, realizando aquela catártica passagem do econômico ao político: a superação de interesses particulares para formular um projeto de dimensão universal, capaz de apresentar uma direção para a sociedade e tornar-se Estado (Gramsci, 1977, p. 1.244). Eis aí sua configuração da sociedade civil: a passagem da estrutura à superestrutura, da economia à política.

E, de acordo com Gramsci, o trabalho dos grupos dominantes para convencer as classes subalternas a aceitar o status quo não se realiza apenas no plano intelectual. A veiculação de idéias é acompanhada da proposição de um modo de agir. Aqui está claro o vínculo dialético estabelecido por Gramsci entre "teoria" e "prática". Quando a classe dominante consegue dar uma direção intelectual para a sociedade, essa direção também é moral, isto é, implica formas de agir no mundo, a prática. A hegemonia é o exercício da direção intelectual e moral da sociedade. 
Por isso, Gramsci ressalta a importância de um movimento intelectual que difunda novas concepçóes de mundo, capazes de elevar a consciência civil das massas populares e de produzir novos comportamentos para que elas não se submetam à direção do Estado capitalista.

É no quadro da disputa pela hegemonia, portanto, que Gramsci aprofunda sua pesquisa sobre a questão da cultura. Para ser uma hegemonia política é preciso organizar a cultura. E o que significa a organização da cultura?

Na teoria de que o Estado é uma "máquina" de repressão da burguesia, que deveria ser quebrada para derrubar o capitalismo ("fórmula de 1848 "), a educação não tinha um lugar importante. Assim, para que organizar a cultura?

Dando uma completa virada nesse modo de entender as idéias e a cultura, Gramsci investiga duas dimensões de organização da cultura. A primeira é a didática, que se refere aos métodos para organizar o pensamento, na qual se destaca o papel educativo da escola, no sentido de oferecer aos filhos das massas trabalhadoras condiçôes para superar as enormes dificuldades em aprender a pensar. A segunda é a organizativa, em relação à qual propõe criar um "centro unitário de cultura". Para o seu funcionamento, toma como referência a sua rica experiência editorial com revistas e jornais do partido socialista e comunista, da qual extrai importantes indicaçóes metodológicas para a atividade educativa das massas populares.

Para tornar o "centro de cultura" hegemônico, Gramsci propõe duas linhas "principais" de ação: uma concepção geral de vida e um programa escolar. A concepção de vida tem como referência o marxismo (a "filosofia da práxis"), que deveria ser aprofundado e desenvolvido; já o programa escolar diz respeito a "um princípio educativo e pedagógico original que interesse e dê uma atividade própria, no seu campo técnico, àquela fração dos intelectuais que é a mais homogênea e a mais numerosa (os professores, do ensino elementar aos professores de Universidades)" (idem, ibid., p. 2.047; grifo meu).

É desenvolvendo o princípio educativo que Gramsci formula a noção de escola unitária. O "princípio unitário" ultrapassa a escola como instituição (Gramsci, 1977, p. 1.538) e se relaciona à luta pela igualdade social, para superar as divisōes de classe, que se expressam na separa- 
ção entre trabalho industrial e trabalho intelectual e dividem a sociedade entre governantes e governados. A "escola unitária" é esboçada como "um esquema de organização do trabalho cultural" (idem, ibid., p. 1.539). Tem como ponto de partida as relaçôes sociais dentro do capitalismo, já que Gramsci não fala em destruir o capitalismo primeiro e somente depois disso cuidar da educação dos trabalhadores. Ele não tem uma visão dicotômica da relação entre Estado e sociedade. A escola unitária está no horizonte de um processo de construção que, por ser dialético, é simultaneamente de destruição.

Quando, na década de 1980, os educadores brasileiros procuraram aprofundar o problema da escola no socialismo, estimulados pela leitura do livro de Gramsci, Os intelectuais e a organização da cultura (1978), teria esse movimento significado a ruptura com a teoria de que a escola é apenas reprodutora do capitalismo? As propostas então apresentadas para a escola no Brasil teriam contribuído para ampliar o debate sobre a luta ideológica e a conquista da hegemonia civil? Teriam contribuído para avançar o pensamento de Gramsci sobre a escola, enriquecendo-o e tornando-o capaz de enfrentar novos desafios sociais e políticos, surgidos desde a Segunda Guerra Mundial, e que o pensador sardo não conheceu?

No caso do Brasil, responder a essas perguntas é, ao mesmo tempo, tratar do tipo de interpretação que acabou prevalecendo na historiografia da educação e nos embates políticos em defesa da escola pública.

\section{Um projeto socialista para a escola pública?}

No âmbito da educação, a leitura do pensamento pedagógico de Gramsci foi acompanhada da retomada da perspectiva vagamente apresentada por Marx sobre a escola, difundida no Brasil como "escola politécnica". A partir de então, "escola unitária" e "escola politécnica" passaram a ser entendidas na literatura educacional brasileira como se fossem a mesma coisa.

Marx (1992), entretanto, não chegou propriamente a elaborar e a defender uma proposta escolar. Ele sustentou princípios gerais para orientar a educação dos trabalhadores, que abrangiam a educação intelectual, a instrução politécnica ou tecnológica e a educação física (a ginástica).

A "instrução tecnológica" ou "instrução politécnica", mais do que uma filosofia educacional, consiste num método de união entre o ensino 
e o trabalho que surge quando é superada a formação profissional especializada, predominante na época em que a produção econômica se baseava no artesanato. É daí que surgem as "escolas agronômicas e politécnicas", criadas pelos filantropos ingleses para habilitar o trabalhador ao exercício de diversas profissões. Por isso, em Marx, a "instrução politécnica" refere-se ao ensino de muitas técnicas. Mas ele não deu à sua proposta o nome de "educação politécnica" ou "educação tecnológica", pois concebia a educação de uma forma bem mais ampla, incluindo também a educação intelectual e física (a ginástica).

Lenin e Krupskaia, por sua vez, retomaram as reflexões de Marx como referência para reduzir a influência da escola nova entre os docentes russos (Lenin, 1975, p. 64), proposta essa que Marx nem conheceu. Formularam as noções de "instrução geral e politécnica" e de "escola única do trabalho" que, mesmo depois de intensos debates, permaneceram ainda muito vagas, reduzindo-se a idéia de trabalho à fábrica (Pistrak, 1981). O esforço de Lenin e Krupskaia ficou condicionado a duas limitaçôes: a situação específica da sociedade russa no conjunto do capitalismo europeu e a influência do economicismo no movimento operário, impedindo que a proposta soviética expressasse uma visão hegemônica do projeto cultural socialista.

Já as concepções de "escola ativa" (ou escola nova), formuladas pelo pensamento liberal burguês no final do século XIX e início do século $\mathrm{XX}$, procuraram responder à crise da escola humanista, abrindo também uma interlocução com as idéias socialistas sobre a escola. Assimilavam reivindicações do movimento operário, como a inclusão do princípio do trabalho na escola e a democratização da cultura, e as subordinavam à sua direção hegemônica. Trata-se, de acordo com a conceituação gramsciana, de um verdadeiro "transformismo": assimilação do "novo" para subjugá-lo ao "velho". Ao propor a democratização da escola, também para responder a demandas de expansão do capitalismo de base industrial, os teóricos da escola ativa redefinem os mecanismos de seleção social da escola de modo a apresentá-la como sendo "única". Mas sua proposta não conseguiu (e nem poderia) deixar de expressar as contradições sociais, que dividem a sociedade em dirigentes e dirigidos, permanecendo dualista: a formação de quadros técnico-científicos (funções de concepção e direção) e de quadros instrumentais (funções de execução, subalternas). 
São as reflexões de Gramsci sobre a sociedade civil e o Estado que permitem esclarecer a "trama" da "escola ativa", o transformismo, e apresentar uma proposta que a supere dialeticamente. A "escola unitária" representa um novo desenvolvimento do conceito socialista de educação e marca uma ruptura dialética com a idéia de "instrução geral e politécnica" ou de "escola única do trabalho", desenvolvida no contexto soviético.

No Brasil, as interpretações mais difundidas do pensamento de Gramsci na área educacional, na década de 1980 e início da de 1990 , foram condicionadas à leitura que confunde "escola unitária" e "politecnia”, feita por Mario Manacorda. O historiador italiano não hesita em afirmar que foi o responsável por tal confusão, quando esteve no Brasil nos anos de 1980 e difundiu suas idéias junto a Dermeval Saviani, ${ }^{1}$ então professor da Pontifícia Universidade Católica de São Paulo (PUC-SP).

Foi justamente na década de 1980 que se discutia no Brasil a elaboração de uma Constituição, que foi aprovada em 1988, dando lugar ao debate sobre uma nova Lei de Diretrizes e Bases para a Educação Nacional (LDB). Não foi por acaso que, nessa época, a Revista Sala de Aula (1989) publicou uma reportagem sobre os "novos politécnicos", que foram entrevistados sobre o "polêmico" conceito de "politecnia" que defendiam como diretriz para a educação nacional.

Os "novos politécnicos" eram leitores de Marx e de Gramsci e seu mestre foi o professor Saviani, para quem a "politecnia" é uma política para o conjunto do sistema nacional de educação, tendo como eixo orientador o trabalho (Revista Sala de Aula, 1989, p. 27). Segundo Saviani, o conceito de politecnia fora proposto por Marx quando estava na Associação dos Trabalhadores (1864) e pensava a revolução socialista mundial. Posteriormente, aquele conceito teria incorporado as reflexôes de Gramsci, que teria proposto o conceito de escola unitária e politécnica, pois representaria para ele uma síntese das ciências da natureza e da história, base da formação do novo homem.

Já na segunda metade dos anos de 1980, Saviani encaminhou uma proposta para a elaboração de projeto para a LDB, baseada no conceito de politecnia que, para ele,

(...) envolve a articulação entre trabalho intelectual e trabalho manual e envolve uma formação a partir do próprio trabalho social que desenvolve os 
fundamentos, os princípios, que estão na base da organização do trabalho em nossa sociedade e que, portanto, nos permitem compreender o seu funcionamento. (Saviani, 1997, p. 19)

Para Saviani (1989, p. 17), a politecnia representa o "domínio dos fundamentos científicos das diferentes técnicas que caracterizam o processo de trabalho produtivo moderno". E, como exemplo de atividades na escola média para desenvolver a politecnia, o autor sugere o trabalho com madeira e metal, alegando que ele "(...) tem imenso valor educativo, pois apresenta possibilidades amplas de transformação. Envolve não apenas a produção da maioria dos objetos que compóem o processo produtivo moderno, mas também a produção de instrumentos com os quais esses objetos serão produzidos" (Saviani, 1997, p. 39).

Assim, para a atividade produtiva moderna, que a partir do final dos anos de 1970 se caracteriza pela microeletrônica e informática, o autor sugere um exemplo de atividade com metal e madeira, cuja introdução nas escolas remonta ao final do século XIX, nos Estados Unidos. Foi o método adotado para despertar o interesse da criança pelo trabalho, por meio da construção de um objeto completo, útil ou ornamental, como explica o pedagogo belga Omer Buyse, cujo livro Méthodes américaines d'éducation générale et technique (1908) foi recomendado pelo educador escolanovista brasileiro Anísio Teixeira, incentivando sua tradução para o português (Buyse, 1927). No Brasil, desde a década de 20 do século passado, "os admiráveis métodos americanos de ensino elementar” (Teixeira, 1927) começaram a ser usados pelo professor Corinto da Fonseca na então "Escola Profissional Sousa Aguiar", no Rio de Janeiro. Foi considerado um método para desespecializar o ensino de ofícios (Fonseca, 1929), no sentido de uma politecnia (muitas técnicas) (Soares, 2000).

Frigotto é outro leitor de Gramsci, então considerado pela Revista Sala de Aula (1989, p. 28) um dos principais formuladores da proposta de politecnia para a escola média. Para ele, a escola politécnica "aceita o desafio da modernidade técnica" (Frigotto, 1988).

Nos anos de 1990, após a queda do muro no leste europeu, Frigotto admite que a tese da "escola unitária" tem "mal entendidos", mas continua a defender que, no campo educacional, o horizonte da luta deve ser a "escola unitária, tecnológica, omnilateral ou politécnica" (Frigotto, 1993, p. 41). No primeiro governo de Luiz Inácio Lula da Silva, essa 
idéia de escola constitui a sua referência para participar da elaboração de um decreto (n. 5.154/2004), instituindo "uma concepção de educação que busca, a partir do desenvolvimento do capitalismo e de sua crítica, superar a proposta burguesa de educação que potencialize a transformação estrutural da realidade" (Frigotto, Ciavatta \& Ramos, 2005; grifo meu).

Frigotto e suas colegas (Ciavatta e Ramos) se desculpam por terem trabalhado na aplicação de um decreto, o que é uma medida autoritária, justificando que, se assim não agissem, "as forças conservadoras ocupariam espaço para fazerem valer seus interesses, tanto no Conselho Nacional de Educação quanto no Congresso" (idem, 2005a). Além disso, afirmam que a instituição de um decreto, por sua rapidez, evitaria um debate com a sociedade civil e um confronto de forças sociais e políticas, que levariam à derrota da proposta da "esquerda progressista".

A noção de politecnia que inspira o decreto, segundo Frigotto, Ciavatta \& Ramos, foi reafirmada por Saviani (2003) como estratégia para a escola, embora tal noção não deva ser interpretada no seu significado literal. Este, como afirma o próprio Saviani (2003, p. 140), "significaria múltiplas técnicas, multiplicidade de técnicas, e daí o risco de se entender esse conceito como a totalidade das diferentes técnicas, fragmentadas, autonomamente consideradas". O termo "tecnologia" seria o mais adequado, mas teria sido apropriado pela burguesia. Justamente por isso, os autores decidem adotar o termo "politecnia", que seria, para eles, o "mais apropriado para definir uma concepção de educação voltada explicitamente para a superação da divisão social do trabalho determinada por uma sociedade cindida em classes" (Frigotto, Ciavatta \& Ramos, 2005). De acordo com Frigotto (2005), Saviani afirma que, enquanto o termo tecnologia se vincula ao tecnicismo e à burguesia, o termo "politecnia" teria sido "preservado na tradição socialista". Assim, mesmo depois de todas as transformaçóes ocorridas desde a queda do "socialismo real", a noção de politecnia seria a mais adequada para que "a educação tecnológica se efetive para os filhos dos trabalhadores" (Frigotto, Ciavatta \& Ramos, 2005; grifo meu).

Não há, portanto, distinções entre a concepção de Marx, a do "socialismo real" e a de Gramsci. Elas são entendidas como sendo idênticas e independentes dos contextos históricos em que foram propostas. Enfim, a ausência de diferenças entre politecnia e escola unitária tem sido a leitura predominante na historiografia da educação brasileira, constitu- 
indo a referência para projetos de política educacional, até autoritariamente instituídos, como é o caso do referido decreto proposto pela "esquerda progressista”.

Mas se o próprio Marx não deu à sua idéia de educação o nome de "politecnia", de onde viria tal denominação reducionista?

Manacorda, como vimos, assume parte da responsabilidade sobre a confusão entre o conceito de politecnia e o de escola unitária no Brasil. Também os "politécnicos" brasileiros se reportam ao historiador italiano para justificar a validade de usar o termo politecnia como referência para um projeto educacional no Brasil, voltado aos interesses da classe trabalhadora (Ciavatta, 2005). Mas isso não responde à pergunta: De onde viria a idéia de que politecnia é a concepção educacional proposta por Marx? E mais: Por que o termo "politecnia" expressaria uma formação "omnilateral" por ter sido "preservado na tradição socialista"?

Certamente, a reflexão de Manacorda sobre a "politecnia” foi acolhida no Brasil. Seus estudos sobre a pedagogia adotada nos países socialistas foram realizados nos anos de 1960, quando o historiador italiano representava a comissão cultural do Partido Comunista Italiano (PCI) e dirigia o periódico Riforma della Scuola. Então, Manacorda elaborou uma trilogia sobre a educação no socialismo, que abrange o pensamento de Marx, Engels e Lênin (1964), a experiência da escola soviética (1965) e a experiência educacional nos países socialistas (1966). Seu argumento é o de que as três fontes que constituem a experiência pedagógica socialista, de forma completa ou parcial, são "análise marxista, modelo soviético e realidade nacional” (Manacorda, 1966, p. 5; grifo meu). De acordo com sua pesquisa, o "marxismo pedagógico" foi "filtrado e refletido pela experiência soviética" (idem, ibid., p. 6) e foi essa interpretação já codificada que foi transmitida aos países que passaram ao bloco socialista, depois da Segunda Guerra Mundial. Assim, uma esquematização da experiência soviética foi exportada para os novos países que ingressaram no bloco soviético, não havendo necessidade de que o marxismo pedagógico fosse "descoberto e discutido ex-novo, como nos primeiros anos do poder soviético" (idem, ibid., p. 6).

O autor faz uma crítica à educação, durante o período de Stalin. Afirma que, embora os termos "politecnia" e "omnilateralidade" tenham sido adotados para a educação, eles perderam seus significados. Politecnia passou a significar 
(...) a multiplicidade de preparações profissionais, a disponibilidade do trabalhador para as diferentes tarefas para as quais pode ser chamado devido às mudanças tecnológicas, silenciando (mesmo que não excluindo) o tema da formação intelectual, da aquisição teórica dos fundamentos das ciências ao lado da capacidade prática do manejo dos instrumentos dos trabalhos (ofícios), em suma, o liame entre ciência e trabalho. (Manacorda, 1966, p. 7)

No entanto, Manacorda defende que, após as denúncias de Kruschev sobre os crimes de Stalin (XX Congresso do Partido Comunista, 1956), houve uma reorientação da política educacional soviética. Então, teria sido recuperado "o significado mais verdadeiro das indicações marxianas" que, para o autor, "é aquele de sugerir não tanto o trabalho manual (que certamente ele sugere), mas o trabalho produtivo, o trabalho de fábrica, porque a fábrica é o modo típico da produção moderna" (Manacorda, 1966, p. 8; grifo meu). Na interpretação de Manacorda, de acordo com Marx, "a instrução deverá voltar-se não tanto a assumir a herança do passado, quanto de inserir-se na perspectiva do presente. Esse processo objetivo cria a nova instrução de fábrica (...)" (idem, ibid.; grifo meu). Assim, é essa idéia de "politecnia" ligada à instrução de fábrica que constitui, para Manacorda, o modelo do socialismo e passou a ser adotada em todos os países do bloco soviético, em torno de 1956-1961.

Em suas diretivas para a educação, Lenin (1975, p. 66) não adotava o termo "politecnia" isoladamente, mas o combinava à educação geral, chamando-a "instrução geral e politécnica". Além disso, ele também pensava a formação de dirigentes, aspecto que foi abandonado pelo socialismo real, o qual ficou restrito à fraseologia do homem "omnilateral" e foi capaz de sufocar qualquer movimento de emancipação, como aconteceu na Hungria (1956), na Polônia (1956) e na Checo-Eslováquia (1968). Nesses países, também havia a experiência da politecnia e da "omnilateralidade", que Manacorda considera uma "pedagogia marxiana”. Mas se para Manacorda a "politecnia” representa o liame entre "instrução e fábrica", uma dimensão econômica da formação escolar, como seria desenvolvida a "omnilateralidade"? Esse é um aspecto que o historiador italiano não aprofunda em seus estudos sobre a experiência do socialismo real. O estreito vínculo de Manacorda com as posições tomadas pelo PCI de alinhamento à União Soviética, mesmo depois das denúncias ao stalinismo, o leva a dizer que as revol- 
tas húngara e polaca de 1956 foram "confusas aspiraçôes por um desenvolvimento mais civil em direção ao socialismo, o patriotismo e o nacionalismo anti-soviético" e "abertas esperanças de restauração capitalista" (Manacorda, 1966, p. 11; grifo meu).

É dessa experiência sobre "politecnia", na qual foram cruelmente sufocadas tentativas de emancipação social e política, que Manacorda extrai suas conclusões sobre uma educação marxista voltada ao desenvolvimento da "omnilateralidade"?

O "socialismo real" foi marcado pela ausência de democracia e por políticas de repressão não apenas em relação às tentativas de "liberalizar" o socialismo, como também por impedir a inovação e o desenvolvimento de associações de trabalhadores e o intercâmbio entre trabalhadores qualificados e pesquisadores científicos (Blackburn, 1993, p. 162). Ali prevaleceram a negação de direitos civis e políticos e a ausência da crítica e do debate, o que impediu a renovação de idéias e favoreceu a difusão de um marxismo fossilizado e dogmático. Por essas características, a organização da escola no "socialismo real", conhecida como "politecnia", não poderia ser considerada uma experiência que expressasse o pensamento marxiano sobre o desenvolvimento da "omnilateralidade".

A síntese de Manacorda sobre a "politecnia", portanto, não é realizada com base na reflexão de Gramsci sobre a escola unitária, mas de acordo com o modelo soviético, do qual está ausente a perspectiva da hegemonia e da formação de dirigentes. Em sua trilogia sobre a pedagogia socialista, Manacorda $(1964,1965,1966)$ sequer se refere a Gramsci. $^{2}$

Mas é a idéia de "politecnia" que constitui, em pleno século XXI, o referencial que inspirou uma política educacional para a escola média, instituída por decreto.

Se a difusão das idéias de Gramsci no Brasil, a partir dos anos de 1980, contribuiu para recuperar a importância da escola pública, que fora desvalorizada ao ser considerada "aparelho ideológico" do Estado, isso não significou a compreensão e o avanço do seu pensamento pedagógico.

Recebido em fevereiro de 2006 e aprovado em abril de 2006. 
Gramsci e o debate sobre a escola pública no Brasil

\section{Notas}

1. Sobre sua influência no Brasil, Manacorda declarou: "De fato, creio que seja também eu, talvez junto a Dermeval Saviani, responsável por essa confusão [entre a concepção de Gramsci e de Marx sobre educação], com minhas lições em seis universidades, dentre as quais a de Minas Gerais (Belo Horizonte) e com o meu livro sobre a História da educação: da Antiguidade aos nossos dias, traduzido pela Cortez, em 1979, e o outro, Marx e a pedagogia moderna, traduzido por Iniciativas Editoriais, em Lisboa, 1975" (Carta de abril de 2001. In: Soares, 2004, p. 4).

2. Segundo Lucio Magri (2001), a difusão das idéias de Gramsci, nos anos de 1950, foi condicionada pelos objetivos políticos de Toglitatti de remodelar o partido e manter a ligação com a União Soviética, fazendo uma leitura fragmentária dos Cadernos do cárcere, de Gramsci, já que a sua reflexão superava posiçôes do PCI e mesmo entrava em contradição com elas.

\section{Referências bibliográficas}

ALTHUSSER, L. Ideologia e aparelhos ideológicos do Estado. Lisboa: Presença, 1974.

APPLE, M.W. Ideology and curriculum. Boston: Routledge, 1979.

AZEVEDO, F. Manifesto dos educadores: mais uma vez convocados. In: BarRos, R.S.M. (Org.). Diretrizes e bases da educação nacional. São Paulo: Pioneira, 1960. p. 57-82.

AZEVEDO, F. A reconstrução educacional no Brasil: manifesto dos pioneiros da educação nova. In: AZEVEDo, F. A educação entre dois mundos. São Paulo: Melhoramentos, 1958. p. 59-81. (Obras completas, v. 16). (O Manifesto dos Pioneiros foi também publicado pela Revista Brasileira de Estudos Pedagógicos, Brasília, DF, n. 79, p. 3-24, jul./set. 1960).

BAUDELOT, C.; ESTABLET, R. La escuela capitalista. México, DF: Siglo Veintiuno, 1976.

BLACKBURN, R. O socialismo após o colapso. In: BLACKBURN, R. (Org.). Depois da queda: o fracasso do comunismo e o futuro do socialismo. Rio de Janeiro: Paz \& Terra, 1993. p. 107-215.

BOURDIEU, P.; PASSERON, J.C. A reprodução: elementos para uma teoria do sistema de ensino. Rio de Janeiro: Francisco Alves, 1975. 
BOWLES, S.; GINTIS, H. Schooling in capitalist America: educational reform and contradictions of economic life. New York: Basic Books, 1976.

BUYSE, O. Méthodes américaines d'éducation générale et technique. Charleroi: Establissement Litho de Charleroi, 1908.

BUYSE, O. Métodos americanos de educação geral e técnica. Salvador: Imprensa Oficial, 1927.

CARNOY, M. La educación como imperialismo cultural. México, DF: Siglo Veintiuno, 1977.

CUNHA, L.A. A atuação de Dermeval Saviani na educação brasileira: um depoimento. In: Silva Junior, C.A. (Org.). Dermeval Saviani e a educação brasileira: o simpósio de Marília. São Paulo: Cortez, 1994. p. 41-62.

CUNHA, L.A. Notas para uma leitura da teoria da violência simbólica. Educação \& Sociedade, Campinas, v. 1, n. 4, p. 79-110, set. 1979.

DORE SOARES, R. Concepção socialista da educação e atuais paradigmas de qualificação para o trabalho: notas introdutórias. Educação \& Sociedade, Campinas, v. 18, n. 58, p. 142-155, abr. 1997.

DORE SOARES, R. Entrevista com Mario A. Manacorda (Encarte). Novos Rumos, São Paulo, v. 19, n. 41, p. 1-23, 2004.

DORE SOARES, R. Gramsci, o Estado e a escola. Ijuí: Unijuí, 2000.

DORE SOARES, R. La scuola unitaria oggi: il caso brasiliano. Rivista Critica Marxista, Roma, n. 2-3, p. 62-68, magg. 2001.

ESTABLET, R. A escola. Tempo Brasileiro, Rio de Janeiro, p. 93-125, out./dez. 1974.

FONSECA, C. A escola ativa e os trabalhos manuais. São Paulo: Melhoramentos, 1929.

FRIGOTTO, G. Formação profissional no $2^{\circ}$ grau: em busca do horizonte da educação politécnica. Cadernos de Saúde Pública, Rio de Janeiro, v. 4, n. 4, p. 435-445, out./dez. 1988. 
FRIGOTTO, G. Trabalho e educação: formação técnico-profissional em questão. Universidade \& Sociedade, São Paulo, n. 5, p. 38-42, 1993.

FRIGOTTO, G. Escola pública da atualidade: lições da história. In: Lombardi, J.C.; Saviani, D.; Nascimento, M.I.M. (Org.). A escola pública no Brasil: história e historiografia. Campinas: Autores Associados, 2005. Disponível em: <http://www.classiserra.com.br/cid/51arq.doc>. Acesso em: 20 fev. 2006.

FRIGOTTO, G.; CIAVATTA, M.; RAMOS, M. A política de educação profissional no Governo Lula: um percurso histórico controvertido. Educação \& Sociedade, Campinas, v. 26, n. 92, p. 1.087-1.113, out. 2005a.

FRIGOTTO, G.; CIAVATTA, M.; RAMOS, M. A gênese do Decreto n. 5.154/2004: um debate no contexto controverso da democracia restrita. Trabalho Necessário, Rio de Janeiro, v. 3, n. 3, 2005 b.

GIROUX, H. Theory and resistance in education: a pedagogy for the opposition. South Hadley, MA: Bergin and Garvey, 1983.

GRAMSCI, A. Os intelectuais e a organização da cultura. Rio de Janeiro: Civilização Brasileira, 1978.

GRAMSCI, A. Quaderni del carcere. Turim: Einaudi, 1977.

ILLICH, I. Sociedade sem escolas. Petrópolis: Vozes, 1973. (Educação e tempo presente, 10).

LENIN, V.I. La instrucción pública. Moscou: Progreso, 1975.

MAGRI, L. Il Gramsci di Togliatti. La Rivista del Manifesto, n. 20, set. 2001. Disponível em: <http://www.larivistadelmanifesto.it/archivio/20/ 20A20010917.html>. Acesso em: 2 mar. 2006.

MANACORDA, M.A. I classici: Marx, Engels, Lenin. In: ManaCordA, M.A. Il marxismo e l'educazione (testi e documenti 1843-1964). Roma: Armando Armando, 1964. v. 1.

MANACORDA, M.A. La scuola sovietica. In: MANACORDA, M.A. Il marxismo e l'educazione (testi e documenti 1843-1964). Roma: Armando Armando, 1965. v. 2. 
MANACORDA, M.A. La scuola nei paesi socialisti. In: MANACORDA, M.A. Il marxismo e l'educazione (Testi e documenti 1843-1964). Roma: Armando Armando, 1966. v. 3.

MANACORDA, M.A. Marx e a pedagogia moderna. Lisboa: Iniciativas Editoriais, 1975.

MANACORDA, M.A. História da educação: da Antiguidade aos nossos dias. São Paulo: Cortez; Autores Associados, 1989.

MARX, K. Manifesto do Partido Comunista. In: Texto, Araraquara, v. 3, p. 13-47, 1977.

MARX, K. Prefácio. In: MARX, K. Contribuição à crítica da economia política. Trad. de Maria Helena Barreiro Alves. 2. ed. São Paulo: Martins Fontes, 1983. p. 26-29.

MARX, K. Instruções aos delegados do Conselho Central Provisório, AIt, 1868. In: MarX, K.; Engels, F. Textos sobre educação e ensino. 2. ed. São Paulo: Moraes, 1992.

MORROW, R.A.; TORRES, C.A. Social theory and education: a critique of theories of social and cultural reproduction. Albany: State University of New York, 1995.

PAIVA, V. Estado e educação popular: recolocando o problema. In: Brandão, C.R. (Org.). A questão política da educação popular. São Paulo: Brasiliense, 1985. p. 79-87.

PAIVA, V. Que política educacional queremos? Educação \& Sociedade, Campinas, v. 7, n. 21, p. 122-140, 1985a.

PAIVA, V. Perspectivas e dilemas da educação popular: introdução e organização. Rio de Janeiro: Graal, 1986. p. 15-60.

PAIVA, V. Produção e qualificação para o trabalho: uma revisão da bibliografia internacional. In: DiAs, F.C. (Org.). Ensino das humanidades: a modernidade em questão. São Paulo: Cortez; Brasília, DF: SENEB, 1991. p. 19-103.

A PALAVRA É... politecnia: uma síntese de ciência, técnica e humanismo; com ela, um grupo de educadores quer revolucionar o 
ensino no país. Sala de Aula, São Paulo, v. 2, n. 13, p. 26-32, ago. 1989.

PISTRAK. Fundamentos da escola do trabalho. São Paulo: Brasiliense, 1981.

POSTMAN, N.; WEINGARTNER, C. Contestação: nova fórmula de ensino. Rio de Janeiro: Expressão e Cultura, 1971.

POUlANTZAS, N. Escola em questão. Tempo Brasileiro, Rio de Janeiro, p. 126-137, out./dez. 1973.

REIMER, E. A escola está morta: alternativas em educação. Trad. de Tony Thompson. Rio de Janeiro: Francisco Alves, 1975.

SAVIANI, D. Escola e democracia. São Paulo: Cortez, 1985.

SAVIANI, D. Sobre a concepção de politecnia. Rio de Janeiro: Fundação Oswaldo Cruz, 1989.

SAVIANI, D. A nova lei da educação: trajetória, limites e perspectivas. Campinas: Cortez, 1997.

SAVIANI, D. O choque teórico da politecnia. Trabalho, Educação \& Saúde, Rio de Janeiro, n. 1, p. 131-152, 2003.

SILVA, T.T. Retomando as teorias da reprodução. Teoria \& Educação, Porto Alegre, v. 1, n. 13, p. 155-179, 1990. 